\title{
Perception of Altered Smile Esthetics by Orthodontists, Dentists, and Laypeople in Riyadh, Saudi Arabia
}

This article was published in the following Dove Press journal: Clinical, Cosmetic and Investigational Dentistry

\author{
Arwa Ahmed Aldeeri ${ }^{\prime}{ }^{\prime}$ \\ Khaled Abdullah Alhababi $\left(\mathbb{D}^{2}\right.$ \\ Fahad Abdullah Algahtani $\mathbb{D}^{3}$ \\ Abrar Abdullah Tounsi (D) $^{4}$ \\ Khalid Ibrahim Albadr (iD ${ }^{5}$ \\ 'Orthodontics and Dentofacial \\ Orthopedics, King Saud University, \\ Riyadh, Saudi Arabia; ${ }^{2}$ Dental \\ Department, Prince Sultan Military \\ Medical City, Riyadh, Saudi Arabia; \\ ${ }^{3}$ Orthodontics and Dentofacial \\ Orthopedics, King Saud Medical City, \\ Riyadh, Saudi Arabia; ${ }^{4}$ Department of \\ Periodontics and Community Dentistry, \\ King Saud University, Riyadh, Saudi \\ Arabia; ${ }^{5}$ Orthodontic Department, \\ Prince Sultan Military Medical City, \\ Riyadh, Saudi Arabia
}

Background: Mini-esthetics is an important concept in orthodontics concerned with relatedness of dentition to the face.

Purpose: We compared the perception of altered smile esthetics between orthodontists, dentists, and laypeople in Riyadh, Saudi Arabia.

Patients and Methods: A total of 216 participants (orthodontists, dentists, and laypeople) were conveniently surveyed. An image representing the ideal smile was altered in terms of buccal corridor, gingival display, and midline diastema. Using Likert scale, participants were asked to rate the attractiveness of the altered images.

Results: The three surveyed groups preferred wide rather than narrow buccal corridors. Also, as the amount of gingival display and midline diastema increased, the smile was rated less attractive. Age of participants was significantly associated with more precise recognition of gingival display and midline diastema, $P<0.05$ and $P<0.001$, respectively.

Conclusion: The concept of an ideal smile holds true across the heterogenous groups we studied despite gender and professional background.

Keywords: dentistry, orthodontics, smile, beauty

\section{Introduction}

Esthetics, as defined by Merriam-Webster dictionary, is "a branch of philosophy dealing with the nature of beauty, art, and taste and with the creation and appreciation of beauty". ${ }^{1}$ It is viewed as a combination of artistic elements guided by science. ${ }^{2}$ Esthetics is central to dentistry when it comes to building a pleasant smile that boosts the individual's confidence and improves their quality-of-life. ${ }^{3-5}$ Not surprisingly, these psychological effects were consistent across reports evaluating individuals of different ethnic backgrounds; and were true for healthy people, head and neck cancer patients, and for children. ${ }^{4-9}$ The recognition of this important role of esthetics has led to rapid development in this field, leading to further sub-dividing the concept into macro-, mini-, and micro-esthetics. ${ }^{10}$

The provision of esthetic dental treatment often involves a multidisciplinary approach. ${ }^{11,12}$ The subjectivity of what an attractive smile looks like may create a mismatch between the dental care provider and the patient, and between the providers themselves. Therefore, several attempts were made to recognize the disparity in recognizing these esthetic aspects of the smile between laypeople and the different dental care providers, such as restorative dentists and orthodontists. ${ }^{13-16}$ For instance,
Correspondence: Arwa Ahmed Aldeeri Tel +966-53-900-4403

Email ArwaAldeeri@gmail.com 
Badran and Mustafa ${ }^{15}$ found that a wide smile with narrow buccal corridors was perceived as the most attractive, and orthodontists were more likely to notice changes in buccal corridors than laypeople. They also reported a stronger influence of smile arc on the perceived smile esthetics when compared to buccal corridors. Another study published by Noureddin et $\mathrm{al}^{17}$ reported that the presence of midline diastema was the least attractive compared to dental spacing in other areas of the arch, likely related to the visible nature of the former and its effect on the overall smile. Additionally, Geron and Atalia ${ }^{14}$ found that up to $1 \mathrm{~mm}$ of gingival display in the maxillary arch during smile and speech had a positive rating. However, as gingival display increased, the rating declined.

In Saudi Arabia, a number of studies investigated the perception of several smile esthetics in different regions of the country. For instance, in a study conducted in the southern region, $11.8 \%$ of the surveyed female students perceived the diastema as a symbol of beauty, whereas $39.3 \%$ thought of it as esthetically acceptable. Nevertheless, the majority (74.1\%) believed that their opinion would depend on the size of diastema. ${ }^{18}$ Another survey of female students in the Western region found that a gingival display of $2 \mathrm{~mm}$ was considered the most attractive across groups of different educational backgrounds. ${ }^{19}$ Another study in the Central region reported that as the gingival display increased, upper incisors were perceived more proclined by dentists and laypeople, irrespective of their actual inclination. ${ }^{20}$ The studies performed in Saudi Arabia used questionnaires with non-standardized smile images, which is in our opinion a drawback that they had in common. ${ }^{19-21}$ We used a questionnaire developed and validated in a Jordanian population, which is ethnically similar to the Saudi nationals. Our aim here is to compare the perception of different traits of smile esthetics, namely: buccal corridor, gingival display and midline diastema, between orthodontists, dentists, and laypeople in Riyadh, Saudi Arabia; and to describe any demographics that influence the perception.

\section{Materials and Methods}

\section{Ethical Considerations}

The study was approved by the ethical committee at Riyadh Elm University, Riyadh, Saudi Arabia (RC/IRB/ 2018/1088) in accordance with the Declaration of Helsinki. Verbal informed consent was approved by the ethical committee and obtained from participants. There was no conflict of interest to disclose.

\section{Sample Size Calculation}

Based on the findings of Abu Alhaija et al, ${ }^{22}$ and utilizing the image perceived as most attractive by general practitioners (1.30 \pm 0.57$)$ and laypeople (1.66 \pm 0.72$)$, using a power of 0.80 and alpha of $5 \%$, the minimum required sample size for each group is 41 participants.

\section{Questionnaire}

We used the same self-administered, close-ended, questionnaire that was developed and validated by Abu Alhaija et al. ${ }^{22}$ In their work, they used an image of a female whose smile was within the standard norms (Figure 1). Then, they made alterations producing a total of 10 altered smile images beside the ideal. Two of the images represented narrow and wide buccal corridors (Figure 2), four had different amounts of gingival display ranging from $1-4 \mathrm{~mm}$ (Figure 3 ), and four other images had different degrees of midline diastema ranging from 1-4 $\mathrm{mm}$ in width (Figure 4). The questionnaire has two sections: a) demographics (nationality, age, gender, marital status and profession) and b) images assessment. On Likert scale (very high $=1$, high $=2$, medium $=3$, low $=4$, and very low $=5$ ), participants ranked the importance of each of the smile esthetics, as well as their gratification of their own smiles, the impact their smiles have on their social lives, and if they wish for any improvements to their smiles. The second section of the questionnaire was composed of a random arrangement of the ideal and altered images developed by Abu Alhaija et al. ${ }^{22}$ Participants were asked to evaluate these images in terms of attractiveness (very attractive $=1$, attractive $=2$, acceptable $=3$, unattractive $=4$, and very unattractive $=5$ ).

\section{Data Collection}

The questionnaire was distributed in electronic and printed format conveniently among orthodontists, dentists, and laypeople in the dental clinics of Riyadh Elm University Hospital

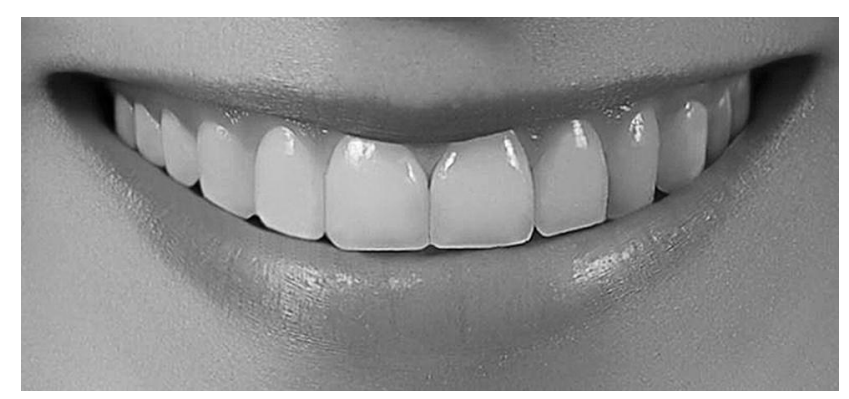

Figure I Ideal smile.

Note: Reproduced from Abu Alhaija ES, Al-Shamsi NO, Al-Khateeb S. Perceptions of Jordanian laypersons and dental professionals to altered smile aesthetics. Eur J Orthod. 20I I;33(4):450-456, by permission of Oxford University Press. ${ }^{22}$ 

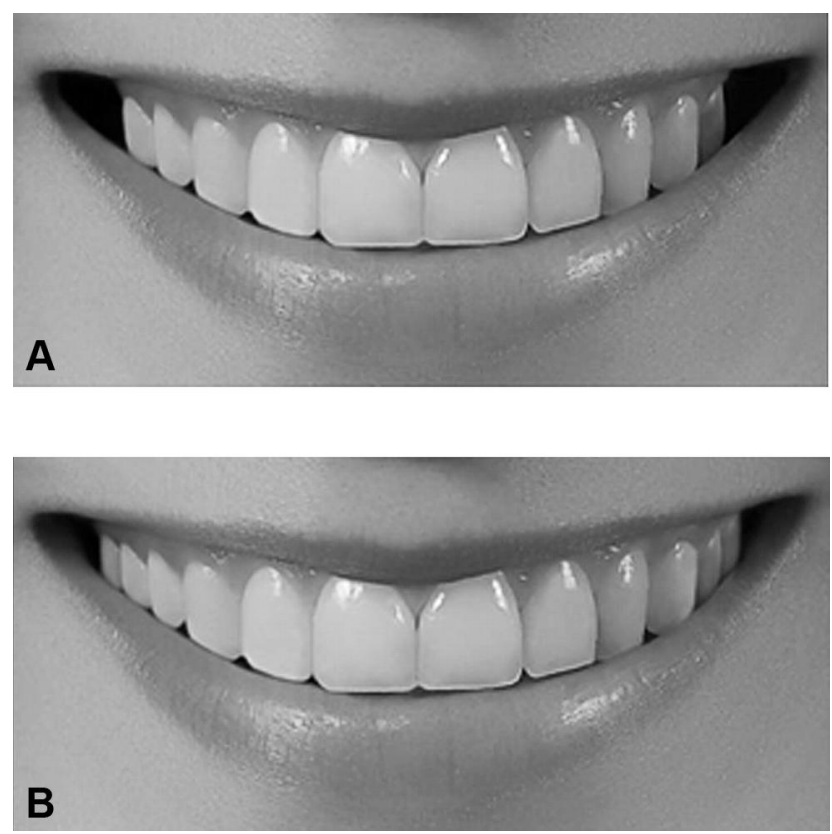

Figure 2 Narrow (A) and Wide (B) buccal corridor spaces.

Note: Reproduced from Abu Alhaija ES, Al-Shamsi NO, Al-Khateeb S. Perceptions of Jordanian laypersons and dental professionals to altered smile aesthetics. Eur J Orthod. 20II;33(4):450-456, by permission of Oxford University Press. ${ }^{22}$

and Prince Sultan Military Medical City in Riyadh, Saudi Arabia. Also, it was distributed among members of the Saudi Orthodontic Society attending the annual scientific meeting.

\section{Statistical Analysis}

Data entry and coding were conducted using Microsoft Excel (MS Excel 2010). All analysis was conducted using SPSS Software version 20 (IBM ${ }^{\circledR}$ SPSS $^{\circledR}$ Statistics). Bivariate analysis was done to compare between groups of professions using chi-square for categorical demographic variables, and one-way ANOVA for continuous variables: the perception of smile attractiveness as well as attractiveness scores of different smiles. Then, general linear models were conducted to determine the effect of profession, gender and age on each of the smile parameters: buccal corridor space, the amount of gingival display, and midline diastema.

\section{Results}

\section{Sample Characteristics}

A total of 216 participants were enrolled in this study, of which 86 were dentists $(39.8 \%), 70$ orthodontists $(32.4 \%)$, and 60 laypeople (27.8\%) (Table 1). The distribution of nationality, age, gender, and marital status was significantly different when grouped based on profession $(P<0.05)$. There were more males $(54.6 \%)$ than females, and $88.4 \%$ of the participants were Saudi nationals. The
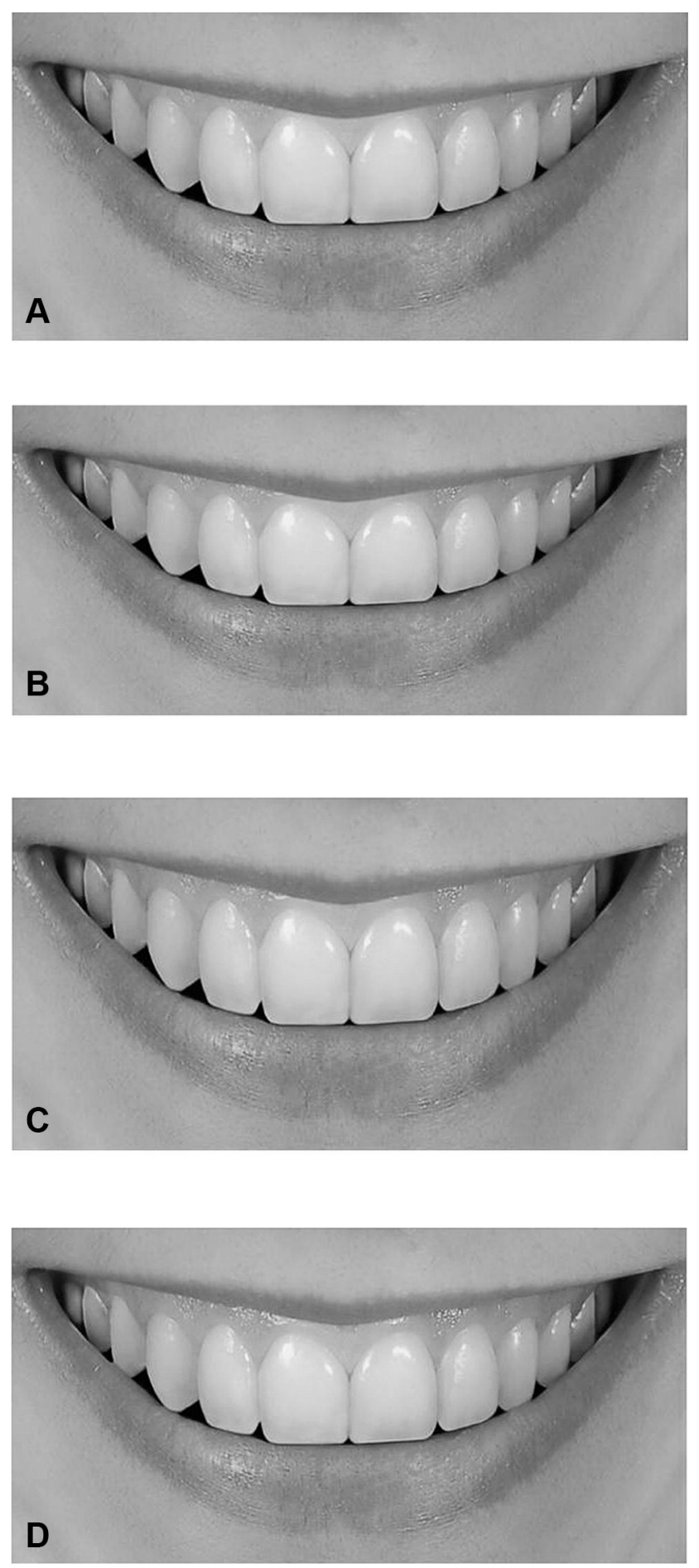

Figure 3 Gingival Display of I (A), 2 (B), 3 (C), and $4 \mathrm{~mm}$ (D).

Note: Reproduced from Abu Alhaija ES, Al-Shamsi NO, Al-Khateeb S. Perceptions of Jordanian laypersons and dental professionals to altered smile aesthetics. Eur J Orthod. 201 1;33(4):450-456, by permission of Oxford University Press. ${ }^{22}$

majority (61.1\%) were younger than 35 years of age, followed by 55 participants (25.4\%) who were 36-44 years, and $29(13.4 \%)$ who were 45 years and above; $55.1 \%$ of the participants were married. 

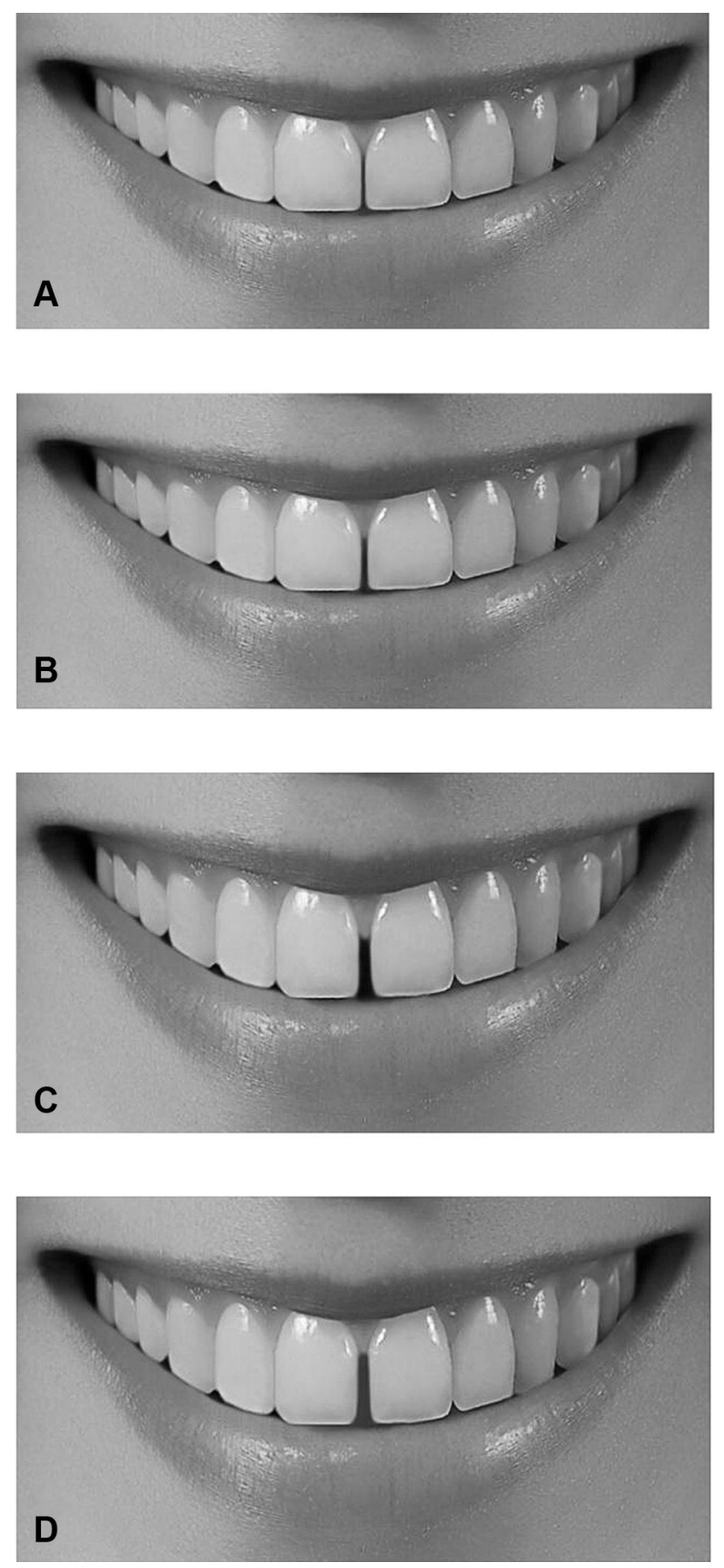

Figure 4 Midline Diastema of I (A), 2 (B), 3 (C), and $4 \mathrm{~mm}$ (D).

Note: Reproduced from Abu Alhaija ES, Al-Shamsi NO, Al-Khateeb S. Perceptions of Jordanian laypersons and dental professionals to altered smile aesthetics. Eur J Orthod. 2011;33(4):450-456, by permission of Oxford University Press. ${ }^{22}$

\section{Self-Perception and Assessment of Images} Significance of an Attractive Smile

The perceived importance of an attractive smile was not significantly different between the groups: highest among orthodontists $(1.19 \pm 0.39)$, followed by dentists $(1.29 \pm 0.48)$ and laypeople (1.32 \pm 0.65$)$.

\section{Smile Satisfaction}

Orthodontists were more self-satisfied with their own smiles $(1.86 \pm 0.75)$ compared to dentists $(1.98 \pm 0.87)$ and laypeople (2.15 \pm 0.76$)$. However, the difference between the groups did not reach the statistical level of significance.

\section{Impact of Smile Esthetics on Social Acceptance}

The perceived impact of smile on social acceptance was significantly higher among orthodontists $(1.49 \pm 0.65)$ compared to laypeople $(2.13 \pm 0.95)$ at $P<0.001$. Also, it was significantly higher among dentists $(1.72 \pm 0.90)$ compared to laypeople $(2.13 \pm 0.95)$ at $P<0.05$.

\section{Impact of an Anterior Spacing on Smile \\ Attractiveness}

Using Likert scale, anterior spacing was ranked to have a high impact by orthodontists $(2.83 \pm 1.25)$ followed by laypeople $(2.85 \pm 1.30)$ and dentists $(2.95 \pm 1.30)$, but this was not statistically significant. Further results are presented in Table 2.

\section{Ideal Smile}

The ideal smile image received an average score of 2.25 \pm 0.05 by all participants, and no gender differences were detected (Table 3). This was set as a cut-off score; images that receive lower scores are considered attractive, while higher scores are considered unattractive. On average, orthodontists provided a higher rating of the ideal smile (2.20 \pm 0.67$)$, followed by dentists $(2.22 \pm 0.72)$ then laypeople (2.33 \pm 0.75$)$. In addition, mean score given by female participants was significantly lower than males, $2.40 \pm 0.71$ and $2.12 \pm 0.68$, respectively (Table 4 ).

\section{Participant's Rating of the Altered Smile Images}

Comparison of attractiveness scores among profession groups and by gender are presented in Table 4. Likert scale ranges from $1-5$, with the smile being most attractive when it receives a score of 1 .

\section{Influence of Buccal Corridors on Perceived Smile Attractiveness}

Compared to narrow buccal corridors, an image with wide buccal corridors was perceived as more attractive by orthodontists, dentists, and laypeople, $2.33 \pm 0.74,2.33 \pm 0.71$, and $2.30 \pm 0.79$, respectively. No statistically significant difference across professions or genders was found (Table 4). 
Table I Distribution of Participants' Demographic Data by Profession

\begin{tabular}{|c|c|c|c|c|}
\hline & $\begin{array}{l}\text { Orthodontists, Frequency (Row \%) } \\
(n=70)\end{array}$ & $\begin{array}{l}\text { Dentists, Frequency (Row \%) } \\
(n=86)\end{array}$ & $\begin{array}{l}\text { Laypeople, Frequency (Row \%) } \\
(n=60)\end{array}$ & $\begin{array}{l}\text { Total } \\
\text { (Col \%) }\end{array}$ \\
\hline \multicolumn{5}{|l|}{ Gender* } \\
\hline Male & 46 (38.9\%) & $58(49.2 \%)$ & $14(11.9 \%)$ & I I 8 (54.6\%) \\
\hline Female & 24 (24.5\%) & $28(28.6 \%)$ & 46 (46.9\%) & $98(45.4 \%)$ \\
\hline \multicolumn{5}{|l|}{ Nationality* } \\
\hline Saudi & 46 (24.1\%) & 85 (44.5\%) & $60(31.4 \%)$ & 191 (88.4\%) \\
\hline Non-Saudi & 24 (96\%) & I (4\%) & 0 & 25 (11.6\%) \\
\hline \multicolumn{5}{|l|}{ Age group* } \\
\hline$<35$ years & $28(21.2 \%)$ & $58(44 \%)$ & $46(34.8 \%)$ & $132(61.1 \%)$ \\
\hline $35-44$ years & 31 (56.4\%) & $18(32.7 \%)$ & $6(10.9 \%)$ & 55 (25.4\%) \\
\hline 45 years and above & II (37.9\%) & $10(34.5 \%)$ & $8(27.6 \%)$ & 29 (13.4\%) \\
\hline \multicolumn{5}{|l|}{ Marital Status* } \\
\hline Single & $16(18 \%)$ & $34(38.2 \%)$ & $39(43.8 \%)$ & $89(41.2 \%)$ \\
\hline Married & 51 (42.9\%) & 48 (40.3\%) & $20(16.8 \%)$ & $119(55.1 \%)$ \\
\hline Divorced & $3(37.5 \%)$ & $4(50 \%)$ & I (12.5\%) & $8(3.7 \%)$ \\
\hline
\end{tabular}

Note: *Significant at $P<0.05$.

Table 2 The Percieved Impact of Smile Attractiveness of Study Population by Profession

\begin{tabular}{|c|c|c|c|}
\hline Question & $\begin{array}{l}\text { Orthodontists, Mean } \pm S D \\
(n=70)\end{array}$ & $\begin{array}{l}\text { Dentists, Mean } \pm \text { SD } \\
(n=86)\end{array}$ & $\begin{array}{l}\text { Laypeople, Mean } \pm S D \\
(n=60)\end{array}$ \\
\hline The importance of an attractive smile for you? & $1.19 \pm 0.39$ & $1.29 \pm 0.48$ & $1.32 \pm 0.65$ \\
\hline Are you satisfied with your smile? & $1.86 \pm 0.75$ & $1.98 \pm 0.87$ & $2.15 \pm 0.76$ \\
\hline The impact of an attractive smile on social acceptance? & $1.49 \pm 0.65$ & $1.72 \pm 0.90$ & $2.13 \pm 0.95^{*}$ \\
\hline $\begin{array}{l}\text { The impact of the presence of spacing between teeth on } \\
\text { smile attractiveness? }\end{array}$ & $2.83 \pm 1.25$ & $2.95 \pm 1.30$ & $2.85 \pm 1.30$ \\
\hline
\end{tabular}

Notes: *Significant at $P<0.05$. Reproduced from Abu Alhaija ES, Al-Shamsi NO, Al-Khateeb S. Perceptions of Jordanian laypersons and dental professionals to altered smile aesthetics. Eur J Orthod. 201 I;33(4):450-456, by permission of Oxford University Press. ${ }^{22}$

\section{Influence of the Amount of Gingival Display on Perceived Smile Attractiveness}

Among different ranges of gingival display, a gingival display of $2 \mathrm{~mm}$ was ranked as the most attractive (2.56 $\pm 0.06)$. A gingival display of $1 \mathrm{~mm}(2.71 \pm 0.06)$, followed by $3 \mathrm{~mm}(3.10 \pm 0.07)$ and $4 \mathrm{~mm}(3.12 \pm 0.06)$ were generally perceived as less attractive (Table 3 ). Male participants rated the $1 \mathrm{~mm}$ of gingival display significantly higher than females $(P<0.05)$ (Table 4$)$.

\section{Influence of the Width of Midline Diastema on Perceived Smile Attractiveness}

Overall, the wider the diastema, the lower score the smile received. Midline diastema of 3 and $4 \mathrm{~mm}$ were ranked as less attractive than $1 \mathrm{~mm}(P<0.05)$ (Table 3$)$. No statistically significant difference across profession and gender groups was found. A minimal diastema of $1 \mathrm{~mm}$ received the highest rating among orthodontists ( $3.17 \pm 0.68)$, dentists ( $3.05 \pm 0.77)$, and laypeople (3.17 \pm 0.79$)$ (Table 4).

\section{Influence of Participants' Age, Gender, and} Profession on the Perceived Attractiveness

Using simple linear models, the influence of age, gender and profession on the perceived smile attractiveness is presented in Table 5. Surprisingly, profession and gender of the participants did not have a significant influence on perception of smile attractiveness. On the other hand, ranking of gingival display ranges and ranking of midline diastema were statistically different between age groups ( $P$-value $<0.05$ and $<0.001$, respectively).

\section{Discussion}

Mini-esthetics is an important concept in orthodontics concerned with relatedness of dentition to the face. It includes analysis of a teeth display in neutral status, while smiling and during speech, in addition to gingival display and the extent of buccal corridors. ${ }^{23}$ For decades, the smile esthetics attracted the interest of researchers, 
Table 3 Attractiveness Scores of Different Smile Variables

\begin{tabular}{|l|l|l|}
\hline Variables & Mean \pm SE & $\mathbf{9 5 \%} \mathbf{~ C l}$ \\
\hline $\begin{array}{l}\text { Smile } \\
\text { Ideal }\end{array}$ & $2.25 \pm 0.05$ & \\
\hline $\begin{array}{l}\text { Buccal corridor space } \\
\text { Narrow }\end{array}$ & & $2.15-2.34$ \\
Wide & $2.65 \pm 0.06$ & \\
\hline Gingival display $(\mathrm{mm})$ & $2.32 \pm 0.05$ & $2.53-2.78$ \\
I & & $2.22-2.42$ \\
2 & $2.71 \pm 0.06$ & \\
3 & $2.56 \pm 0.06$ & $2.59-2.83$ \\
4 & $3.10 \pm 0.07^{*}$ & $2.45-2.68$ \\
\hline Midline diastema (mm) & $3.12 \pm 0.06^{*}$ & $2.97-3.22$ \\
I & & $3.01-3.24$ \\
2 & $3.12 \pm 0.05$ & \\
3 & $3.35 \pm 0.05$ & $3.02-3.22$ \\
4 & $4.19 \pm 0.05^{*}$ & $4.25-3.45$ \\
\hline
\end{tabular}

Note: *Significant at $P<0.05$.

with culture, ${ }^{24}$ ethnicity, ${ }^{25}$ gender ${ }^{14}$ and profession ${ }^{16}$ being suggested as influencing factors. Although several studies evaluated similar outcomes in different populations, a shared pitfall between the studies we came across was the absence of replication of results using the same questionnaires and images in an other population. This study addresses this issue by using a questionnaire developed and validated by Abu Alhaija et $\mathrm{al}^{22}$ in a closely related ethnic population with a similar socioeconomical background. A total of 216 participants, of which $54.63 \%$ were males, were conveniently surveyed. Demographic data are presented in Table 1.

The perceived impact of smile attractiveness by orthodontists and dentists was found to be higher than laypeople (Table 2). Across professions, orthodontists were more exacting in terms of altered smile esthetics (Table 4). This finding is supported by other reports compared between orthodontists and laypeople. ${ }^{26-28}$ Also, and in agreement with Abu Alhaija et al, ${ }^{22}$ a higher tolerance was noticed among female participants compared to males.

In contrast to what Abu Alhaija et al $^{22}$ reported, we did not find a difference in rating smile esthetics when the participants were grouped based on gender and profession. Other studies showed no difference between genders. ${ }^{14,29}$ Also, we found that the rating of gingival display and midline diastema was influenced by age of participants $(P<0.05$ and $<0.001$, respectively), which is in agreement with what the work of Pithon et $\mathrm{al}^{30}$ showed.

Overall, an image representing the ideal standards of smile esthetics was perceived as the most attractive

Table 4 Distribution of Attractiveness Scores of Different Smile Variables Across Profession Groups and Gender

\begin{tabular}{|c|c|c|c|c|c|}
\hline \multirow[t]{2}{*}{ Variables } & \multicolumn{3}{|l|}{ Profession } & \multicolumn{2}{|l|}{ Gender } \\
\hline & $\begin{array}{l}\text { Orthodontists, Mean } \\
( \pm S D) \\
(n=70)\end{array}$ & $\begin{array}{l}\text { Dentists, Mean }( \pm S D) \\
(n=86)\end{array}$ & $\begin{array}{l}\text { Laypeople, Mean } \\
( \pm S D) \\
(n=60)\end{array}$ & $\begin{array}{l}\text { Male, Mean ( } \pm S D) \\
(n=\mid 18)\end{array}$ & $\begin{array}{l}\text { Female, Mean }( \pm S D) \\
(n=98)\end{array}$ \\
\hline Ideal & $2.20(0.67)$ & $2.22(0.72)$ & $2.33(0.75)$ & $2.12(0.68)$ & $2.40(0.7 I)^{*}$ \\
\hline $\begin{array}{l}\text { Buccal corridor space } \\
\text { Narrow } \\
\text { Wide }\end{array}$ & $\begin{array}{l}2.76(0.94) \\
2.33(0.74)\end{array}$ & $\begin{array}{l}2.72(0.92) \\
2.33(0.71)\end{array}$ & $\begin{array}{l}2.43(0.91) \\
2.30(0.79)\end{array}$ & $\begin{array}{l}2.55(0.94) \\
2.35(0.68)\end{array}$ & $\begin{array}{l}2.78(0.90) \\
2.29(0.79)\end{array}$ \\
\hline $\begin{array}{l}\text { Gingival display }(\mathrm{mm}) \\
1 \\
2 \\
3 \\
4\end{array}$ & $\begin{array}{l}2.79(0.99) \\
2.49(0.89) \\
3.03(0.98) \\
3.01(0.88)\end{array}$ & $\begin{array}{l}2.60(0.91) \\
2.58(0.91) \\
3.08(0.99) \\
3.20(0.85)\end{array}$ & $\begin{array}{l}2.77(0.81) \\
2.63(0.86) \\
3.20(0.86) \\
3.13(0.85)\end{array}$ & $\begin{array}{l}2.57(0.91) \\
2.47(0.84) \\
3.05(1.02) \\
3.10(0.87)\end{array}$ & $\begin{array}{l}2.88(0.89)^{*} \\
2.68(0.94) \\
3.15(0.87) \\
3.14(0.85)\end{array}$ \\
\hline $\begin{array}{l}\text { Midline diastema }(\mathrm{mm}) \\
1 \\
2 \\
3 \\
4\end{array}$ & $\begin{array}{l}3.17(0.68) \\
3.39(0.73) \\
4.23(0.62) \\
4.20(0.74)\end{array}$ & $\begin{array}{l}3.05(0.77) \\
3.35(0.69) \\
4.22(0.76) \\
4.27(0.74)\end{array}$ & $\begin{array}{l}3.17(0.79) \\
3.30(0.83) \\
4.12(0.69) \\
3.98(0.89)\end{array}$ & $\begin{array}{l}3.06(0.74) \\
3.28(0.71) \\
4.19(0.73) \\
4.19(0.75)\end{array}$ & $\begin{array}{l}3.19(0.74) \\
3.43(0.77) \\
4.20(0.66) \\
4.14(0.83)\end{array}$ \\
\hline
\end{tabular}

Note: *Significant at $P<0.05$. 
Table 5 Effect of Age, Gender, and Profession on Smile Attractiveness Scores

\begin{tabular}{|l|l|l|l|l|l|l|}
\hline \multirow{2}{*}{ Variables } & \multicolumn{2}{l|}{ Age } & \multicolumn{2}{l|}{ Gender } & \multicolumn{2}{l|}{ Profession } \\
\cline { 2 - 7 } & F & P & F & $\boldsymbol{P}$ & F & P \\
\hline Buccal corridor space & 1.24 & 0.29 & 0.73 & 0.39 & 1.24 & 0.29 \\
Gingival display & 3.10 & $0.04 *$ & 3.32 & 0.07 & 0.39 & 0.68 \\
Midline diastema & 7.94 & $0.00^{*}$ & 0.62 & 0.43 & 0.53 & 0.59 \\
\hline
\end{tabular}

Note: *Significant at $P<0.05$.

(Table 3). This is likely due to the effect of media and standardizing what an ideal smile should look like. Second to the ideal smile, a smile with wide buccal corridors was generally preferred by the participants. This is in contrast to the finding of narrow buccal corridors being more attractive in the Jordanian population. ${ }^{22}$

The more there is of gingival display and the wider the midline diastema, the lower rating the smile received. A gingival show of $2 \mathrm{~mm}$ was rated as most attractive (2.56 \pm 0.06 ). This finding stands between two others reported by similar studies, Geron and Atalia ${ }^{14}$ and Kokish et $\mathrm{al}^{13}$ (1 and $3 \mathrm{~mm}$, respectively). Smiles with different ranges of midline spacing consistently received lower ratings, with spacings of 3 and $4 \mathrm{~mm}$ being even less attractive than $1 \mathrm{~mm}(P<0.05)$. Interestingly, midline spacing was, and probably still is, considered a sign of beauty by some cultures, especially African people; It was even created sometimes artificially. ${ }^{31,32}$ This is not surprising as the African population have their unique characteristics and cultural norms.

\section{Conclusion}

Out of 10 altered smiles and an ideal smile, the ideal smile was perceived as the most attractive smile followed by a smile with wide buccal corridors. More gingival display and midline diastema were not positively perceived, with increased gingival display being better tolerated than increased midline diastema. With the limitations of this study, it appears that the concept of an ideal smile holds true across the heterogenous groups we studied, despite gender and professional background. Whether this high degree of agreement on the perfect smile esthetics is a natural instinct and naturally occurring understanding or it is imposed by the media and advertised by the influencers is something to be answered, especially that some of the less exposed to the media, as in some African regions, seem to hold different esthetic values.

\section{Recommendations}

Results of this study need to be tested at a larger scale in other regions of Saudi Arabia and in other communities, as it is likely there is variation in the perception among communities. Likewise, it will be informative to learn how workers in other dental specialties, like prosthodontists, compare to the specialties we studied here, namely orthodontists, dentists, and laypeople.

To understand the underlying determinants of the differences in perception among different groups, future work can examine factors not studied in this article, such as level of education and socioeconomical status. As we notice different esthetic values especially in cultures less exposed to the media, it will be interesting to explore whether what is today perceived as an ideal smile is imposed by the media and other influencers rather than being natural perception.

\section{Disclosure}

The authors certify that they have neither competing interests nor financial support in the subject matter discussed in this manuscript.

\section{References}

1. Aesthetic. Merriam-Webster. Available from: https://www.merriamwebster.com/dictionary/aesthetic. Accessed February 11, 2020.

2. Acharya P. Facial aesthetics: concepts and clinical diagnosis. Br Dent J. 2011;211(6):298. doi:10.1038/sj.bdj.2011.818

3. Klages U, Rost F, Wehrbein H, Zentner A. Perception of occlusion, psychological impact of dental esthetics, history of orthodontic treatment and their relation to oral health in naval recruits. Angle Orthod. 2007;77(4):675-680. doi:10.2319/061206-237.1

4. Isiekwe GI, Sofola OO, Onigbogi OO, Utomi IL, Sanu OO, Dacosta OO. Dental esthetics and oral health-related quality of life in young adults. Am J Orthod Dentofacial Orthop. 2016;150(4):627-636. doi:10.1016/j.ajodo.2016.03.025

5. Alsuhimi I, Alshouibi A, Alotaibi A, et al. The association between perception of dental esthetic and oral health related quality of life in adolescents in Dammam, Saudi Arabia. Saudi Dent J. 2019;31:S12. doi:10.1016/j.sdentj.2019.01.029

6. Paula JDFD, Santos NCM, Silva ÉTD, Nunes MF, Leles CR. Psychosocial impact of dental esthetics on quality of life in adolescents. Angle Orthod. 2009;79(6):1188-1193. doi:10.2319/082608452r. 1

7. Barbier L, Pottel L, Ceulaer JD, et al. Evaluation of quality of life after mandibular reconstruction using a novel fixed implant-supported dental prosthesis concept: a pilot study. Int J Prosthodont. 2019;32 (2):162-173. doi:10.11607/ijp.6001 
8. Feldens CA, Senna RA, Vargas-Ferreira F, Braga VS, Feldens EG, Kramer PF. The effect of enamel fractures on oral health-related quality of life in adolescents. Dent Traumatol. 2019;36(3):247-252. doi:10.1111/edt.12526

9. Sadana G, Gupta T, Rai HK. Effect of esthetic defects in anterior teeth on the emotional and social well-being of children: a survey. Int J Clin Pediatr Dentis. 2019;12(3):229-232. doi:10.5005/jp-journals10005-1628

10. Sarver DM. The importance of incisor positioning in the esthetic smile: the smile arc. Am J Orthod Dentofacial Orthop. 2001;120 (2):98-111. doi:10.1067/mod.2001.114301

11. de Almeida Cardoso M, de Molon RS, de Avila ED, et al. Facial and occlusal esthetic improvements of an adult skeletal Class III malocclusion using surgical, orthodontic, and implant treatment. Korean $J$ Orthod. 2016;46(1):42. doi:10.4041/kjod.2016.46.1.42

12. Sabatoski CV, Bueno RC, Pacheco AAR, Pithon MM, Tanaka OM. Combined periodontal, orthodontic, and prosthetic treatment in an adult patient. Case Rep Dent. 2015;2015:1-6. doi:10.1155/2015/ 716462

13. Kokich VO, Kiyak HA, Shapiro PA. Comparing the perception of dentists and lay people to altered dental esthetics. J Esthet Restor Dent. 1999;11(6):311-324. doi:10.1111/j.1708-8240.1999.tb00414.x

14. Geron S, Atalia W. Influence of sex on the perception of oral and smile esthetics with different gingival display and incisal plane inclination. Angle Orthod. 2005;75(5):778-784.

15. Badran SA, Mustafa M. A comparison between laypeople and orthodontists in evaluating the effect of buccal corridor and smile arc on smile esthetics. $J$ World Fed Orthod. 2013;2(3):e123-e126. doi:10.1016/j.ejwf.2013.05.005

16. Pisulkar SK, Agrawal R, Belkhode V, Nimonkar S, Borle A, Godbole SR. Perception of buccal corridor space on smile aesthetics among specialty dentist and layperson. J Int Soc Prev Community Dent. 2019;9(5):499-504.

17. Noureddine A, Fron Chabouis H, Parenton S, Lasserre JF. Laypersons' esthetic perception of various computer-generated diastemas: a pilot study. J Prosthet Dent. 2014;112(4):914-920. doi:10. 1016/j.prosdent.2013.10.015

18. Alshahrani I, Togoo R, Alshahrani A, Alshahrani A, Alshehri D. Esthetic perception of maxillary midline diastema among female students at King Khalid University. [online] Pdfs.semanticscholar. org; 2020. Available from: https://pdfs.semanticscholar.org/0e03/ $223617 d 5135 b 4085 b 0 b 450126 b 46 d 0 a 89179 . p d f ?$ ga=2.174916194. 1168133240.1594288973-700630963.1569228462. Accessed June $11,2020$.

19. Zawawi KH, Malki GA, Al-Zahrani MS, Alkhiary YM. Effect of lip position and gingival display on smile and esthetics as perceived by college students with different educational backgrounds. Clin Cosmet Investig Dent. 2013;5:77-80. doi:10.2147/CCIDE.S53359
20. Alyami A, Sanea J, Togoo R, Ain T. Aesthetic perception about gingival display on maxillary incisor inclination among saudi dentists, orthodontist and lay persons. J Clin Diagn Res. 2018. doi:10.7860/JCDR/2018/33965.11835

21. Talic N, AlOmar S, AlMaidhan A. Perception of Saudi dentists and lay people to altered smile esthetics. Saudi Dent J. 2013;25(1):13-21. doi:10.1016/j.sdentj.2012.09.001

22. Abu Alhaija ES, Al-Shamsi NO, Al-Khateeb S. Perceptions of Jordanian laypersons and dental professionals to altered smile aesthetics. Eur J Orthod. 2011;33(4):450-456. doi:10.1093/ejo/cjq100

23. Sarver DM. Interactions of hard tissues, soft tissues, and growth over time, and their impact on orthodontic diagnosis and treatment planning. Am J Orthod Dentofacial Orthop. 2015;148(3):380-386. doi:10.1016/j.ajodo.2015.04.030

24. McLeod C, Fields HW, Hechter F, Wiltshire W, Rody W, Christensen J. Esthetics and smile characteristics evaluated by laypersons. Angle Orthod. 2011;81(2):198-205. doi:10.2319/060510-309.1

25. Sadrhaghighi AH, Zarghami A, Sadrhaghighi S, Mohammadi A, Eskandarinezhad M. Esthetic preferences of laypersons of different cultures and races with regard to smile attractiveness. Indian J Dent Res. 2017;28(2):156-161. doi:10.4103/0970-9290.207795

26. Sarver D, Jacobson RS. The aesthetic dentofacial analysis. Clin Plast Surg. 2007;34(3):369-394. doi:10.1016/j.cps.2007.05.008

27. Olivares A, Vicente A, Jacobo C, Molina SM, Rodríguez A, Bravo LA. Canting of the occlusal plane: perceptions of dental professionals and laypersons. Med Oral Patol Oral Cir Bucal. 2013;18(3):e516. doi: $10.4317 /$ medoral.18335

28. Farzanegan F, Jahanbin A, Darvishpour H, Salari S. Which has a greater influence on smile esthetics perception: teeth or lips? Iran J Otorhinolaryngol. 2013;25(73):239.

29. España P, Tarazona B, Paredes V. Smile esthetics from odontology students' perspectives. Angle Orthod. 2014;84(2):214-224. doi:10.2319/032013-226.1

30. Pithon MM, Matos VO, Coqueiro RDS. Upper incisor exposure and aging: perceptions of aesthetics in three age groups. $J$ World Fed Orthod. 2015;4(2):57-62. doi:10.1016/j.ejwf.2015.02.002

31. Onyeaso CO. Prevalence of malocclusion among adolescents in Ibadan, Nigeria. Am J Orthod Dentofacial Orthop. 2004;126 (5):604-607. doi:10.1016/j.ajodo.2003.07.012

32. Umanah A, Omogbai AA, Osagbemiro B. Prevalence of artificially created maxillary midline diastema and its complications in a selected nigerian population. Afr Health Sci. 2015;15(1):226-232. doi:10.4314/ahs.v15i1.29
Clinical, Cosmetic and Investigational Dentistry

\section{Publish your work in this journal}

Clinical, Cosmetic and Investigational Dentistry is an international, peer-reviewed, open access, online journal focusing on the latest clinical and experimental research in dentistry with specific emphasis on cosmetic interventions. Innovative developments in dental materials, techniques and devices that improve outcomes and patient satisfaction and preference will be highlighted. The manuscript management system is completely online and includes a very quick and fair peer-review system, which is all easy to use. Visit http://www.dovepress.com/testimonials.php to read real quotes from published authors. 